\title{
Editorial
}

\section{Stiff-man syndrome}

Stiff-man syndrome (SMS) is a rare neurological disorder first described by Moersch and Woltman in $1956 .{ }^{1}$ The syndrome is of insidious onset, usually in the fourth or fifth decades, and affects both sexes equally. ${ }^{2}$ Painful involuntary stiffness of the back due to continuous contraction of lumbar and abdominal muscles is the earliest symptom. Axial rigidity progresses slowly over months or years and is accompanied by spasms. Spontaneous spasmodic attacks occur in the majority of patients and are preceded by an aura-like feeling in some patients. ${ }^{3}$ A stereotyped motor pattern is seen during these attacks, which consists of brief opisthotonos, stiffening of the slightly abducted legs and inversion of the plantar-fixed feet. Spasms are precipitated by voluntary movement, fright or sound and may be painful. A characteristic hyperlordosis of the lumbar spine is produced, due to contraction of thoracolumbar paraspinal muscles and abdominal wall rigidity. ${ }^{4}$ Proximal limb muscles are affected later, but face and distal limbs are generally spared. The axial and proximal limb muscle rigidity is aggravated by sensory stimuli and abolished by sleep and anaesthesia. ${ }^{1}$ As the disease progresses, the voluntary movements of the trunk and legs become slow and restricted.

The pathophysiology of SMS is ill understood. It may be an autoimmune disease, based on its frequent association with a number of autoimmune diseases and the findings of a variety of autoantibodies. Insulin-dependent diabetes mellitus (IDDM) is present in one- to two-thirds of patients. ${ }^{5}$ Autoimmune thyroid disease, pernicious anaemia, vitiligo, myasthenia gravis, thymoma, alopecia totalis and certain malignancies are more common in SMS patients, while epilepsy occurs in $10 \%$ of patients. ${ }^{7}$

Autoantibodies against gamma-aminobutyric acid (GABA)-ergic neurons have been detected in serum and cerebrospinal fluid in $60 \%$ of patients with a clinical diagnosis of SMS. ${ }^{6}$ In one series, ${ }^{8}$ thyrogastric antibodies were more frequent in patients with SMS (46\%) than in those with other neurological disorders (12\%). Islet-cell antibodies and anti-glutamic acid decarboxylase (anti-GAD) antibodies were more common in the SMS patients $(38 \%$ and $31 \%$, respectively) than in the patients with other neurological disorders ( $6 \%$ and $3 \%$, respectively). Four of the 13 patients with SMS had an associated solid tumour and three had antibodies to $125 / 130 \mathrm{kd}$ protein (paraneoplastic variant). Autoantibodies against amphiphysin (a protein associated with synaptic vesicles and expressed in

\section{Clinical features of SMS}

- painful involuntary stiffness of the back is the earliest symptom

- spontaneous spasmodic attacks occur in a majority of patients

- spasms are precipitated by voluntary movement, fright or sound

- hyperlordosis of the lumbar spine is produced due to contraction of thoracolumbar paraspinal muscles and abdominal wall rigidity

- the axial and proximal limb muscle rigidity is aggravated by sensory stimuli and abolished by sleep and anaesthesia

- in late stages, the voluntary movements of the trunk and legs become slow and restricted

Box 1

\begin{tabular}{|l|}
\hline Diseases associated with SMS \\
\hline IDDM \\
autoimmune thyroid disease \\
pernicious anaemia \\
- vitiligo \\
myasthenia gravis \\
thymoma \\
- malignancy \\
- epilepsy
\end{tabular}

Box 2

\section{Autoantibodies found in SMS \\ - against GABA-ergic neurons \\ - thyrogastric antibodies \\ - islet-cell antibodies \\ - anti-GAD antibodies \\ - antibodies to $125 / 130 \mathrm{kd}$ protein \\ - autoantibodies against amphiphysin}

Box 3

many neurons, certain endocrine cell types and spermatocytes) have been described in patients with paraneoplastic SMS. ${ }^{910}$

Electromyography of affected muscles reveals nonspecific findings and demonstrates involuntary motor unit activity. The appearance and firing pattern of motor units are normal except that agonist and antagonist muscles may contract concurrently. ${ }^{11}$ Peripheral nerve conduction is normal. Oligoclonal IgG bands have been reported in several cases. ${ }^{12-14}$ Association with HLA B $44^{15}$ antigen and $\mathrm{DR} 3^{14}$ and 4 antigens have been reported.

An imbalance between descending aminergic effects and the inhibitory effects of GABA in the brainstem and the spinal cord has been suggested as a cause of abnormal excitability of spinal interneuronal networks. ${ }^{817-22}$ This hypothesis is supported by the observations that the drugs that increase aminergic (noradrenergic or serotonergic) activity in the central nervous system such as levodopa, ${ }^{20}$ clomipramine, ${ }^{17}$ reserpine $^{17}$ and metamphetamine, ${ }^{18}$ increase the severity of spasms, while those that reduce central catecholamine effects, such as clonidine ${ }^{17-18}$ and tizanidine, ${ }^{18}$ or enhance GABA activity (baclofen or benzodiazepines), diminish the spasms.

Benzodiazepines and baclofen help reduce spasms. Other drugs used with reported benefit are sodium valproate, tizanidine, vigabatrin, ${ }^{23}$ and botulinum toxin $\mathrm{A} .{ }^{24}$ Favourable responses to plasmapheresis ${ }^{25}$ and intravenous immunoglobulin therapy ${ }^{26}$ have also been reported. Plasmapheresis has been used alone and in conjunction with steroids.

In conclusion, research findings support the theory of central nervous system autoimmunity with resultant impairment of neuronal pathways as the probable pathogenesis of stiff-man syndrome. 
SMS is a heterogenous disorder and can be divided into three main types:

- patients (mostly female) with associated autoimmune diseases (mainly IDDM), who are positive for isletcell antibodies and anti-GAD antibodies but negative for non-organ-specific autoantibodies (autoimmune SMS).

- patients (mostly male) with associated neoplasms and non-organ-specific autoantibodies who are negative for islet-cell autoantibodies; SMS patients with no other associated clinical condition but with high GAD

1 Moersch FP, Woltman HW. Progressive fluctuating muscular rigidity and spasm (stiff-man syndrome): report of a case and some observations in 13 other cases. Mayo Clin Proc 1956;31:421-7.

2 Blum P, Jancovic J. Stiff-person syndrome: an autoimmune disease. Mov Disord 1991;6:12-20.

3 Meinck HM, Ricker K, Hulser PJ, Schmid E, Peiffer J, Solimena M. Stiff man syndrome: clinical and laboratory findings in eight patients. $\mathcal{F}$ Neurol 1994;241:157-66.

4 Lorish TR, Thorsteinsson G, Howard FM. Stiff-man syndrome updated. Mayo Clin Proc 1989;64:629-36.

5 Gordon EE, Januszko DM, Kaufman L. A critical survey of stiff-man syndrome. Am $\mathcal{F}$ Med 1967;42:582-99.

6 Solimena M, Folli F, Bottazzo GP, Toso V, DeCamilli P. Autoantibodies to GABAergic neurons and pancreatic beta cells in stiff-man syndrome. $N$ Engl GABAergic neurons and panc

7 Martinelli P, Pazzaglia P, Montagna P, et al. Stiff-man syndrome associated Martinelli $P$, Pazzaglia $P$, Montagna $P$, et al. Stiff-man syndrome associated
with nocturnal myoclonus and epilepsy. $\mathcal{F}$ Neurol Neurosurg Psychiatry 1978 ; $1: 458-62$.

8 Grimaldi LM, Martino G, Braghi S, et al. Heterogeneity of autoantibodies in stiff-man syndrome. Ann Neurol 1993;34:57-64.

Yamamoto R, Li X, Francke U, Kilimann MW. Primary structure of human amphiphysin, the dominant autoantigen of paraneoplastic stiff-man syndrome, and mapping of its gene (AMPH) to chromosome 7P13-P14. Hum Mol Genet 1995;4:265-8.

10 David C, Solimena M, De Camilli P. Autoimmunity in stiff-man syndrome with breast cancer is targeted to the $\mathrm{C}$ - terminal region of human amphiphysin, a protein similir to the yeast proteins, Rvs167 and Rvs161. FEBS Lett 1994;351:73-9.

11 Auger RG. AAEM minimonograph 44: Diseases associated with excess motor unit activity. Muscle Nerve 1994;17:1250-63.

12 Meinck H-M, Ricker K. Long standing stiff-man syndrome: a particular form of disseminated CNS disease? I Neurol Neurosurg Psychiatry 1987;20: $1556-7$ antibodies or organ-specific autoantibodies (paraneoplastic SMS)

- patients with no other associated clinical condition but a high prevalence of non-organ-specific autoantibodies, anti-GAD antibodies, or organ-specific antibodies (idiopathic SMS).

H U REHMAN

Department of Medicine, Hull Royal Infirmary, Anlaby Road, Hull HU3 2fZ, UK

Accepted 23 April 1998

Keywords: stiff-man syndrome; autoimmune disease

13 Harding AE, Thompson PD, Kocen RS, et al. Plasma exchange and immunosuppression in the stiff-man syndrome. Lancet 1989;ii:915.

14 Williams AC, Nutt JG, Hare T. Autoimmunity in stiff-man syndrome. Lancet 1988;ii:22.

15 Solimena M, Folli F, Denis-Donini S, et al. Autoantibodies to glutamic acid decarboxylase in a patient with stiff-man syndrome, epilepsy and type 1 diabetes mellitus. N Engl F Med 1988;318:1012-20.

16 Asher R. A woman with the stiff-man syndrome. BMF 1958;I:265-6.

17 Meinck HM, Ricker K, Conrad B. The stiff-man syndrome: new pathophysiological aspects from abnormal exteroceptive reflexes and the response to clomipramine, clonidine and tizanidine. $\mathcal{f}$ Neurol Neurosurg Psychiatry 1984;47:280-7.

18 Meinck HM, Conrad B. Neuropharmacological investigations in the stiff-man syndrome. $¥$ Neurol $1986 ; 3: 114-22$.

19 Leigh PN, Rothwell JC, Traub M, Marsden CD. A patient with reflex myoclonus and muscle rigidity 'jerking stiff-man syndrome'. $\mathcal{F}$ Neurol Neurosurg Psychiatry 1980;43:1125-31.

20 Guilleminault C, Sigwald J, Castaigne P. Sleep studies and therapeutic trial with L-Dopa in a case of stiff-man syndrome. Eur Neurol 1973;10:89-96.

21 Mamoli B, Heiss WD, Maida E, Podreka I. Electrophysiological studies on the stiff-man syndrome. $\mathcal{F}$ Neurol 1977;217:111-21.

22 Baekkeskov S, Aanstoot H-J, Christgau S, et al. Identification of the $64 \mathrm{~K}$ autoantigen in insulin dependent diabetes mellitus as the GABAsynthesising enzyme glutamic acid decarboxylase. Nature 1990;347:151-6. 23 Prevett MC, Brown P, Duncan JS. Improvement of stiff-man syndrome with vigabatrin. Neurology 1997;48:1133-4.

24 Davis D, Jabbari B. Significant improvement of stiff-person syndrome after paraspinal injection of botulinum toxin A. Mov Disord 1993;8:371-3.

25 Vicari AM, Folli F, Pozza G, et al. Plasmapharesis in the treatment of stiffman syndrome. N Engl F Med 1989;320:1499.

26 Karlson EW, Sudarsky L, Ruderman E, Pierson S, Scott M, Helfgott SM. Treatment of stiff-man syndrome with intravenous immunoglobulin. Arthritis Rheum 1994;37:915-8.

\section{Amiodarone-induced cornea verticillata}

A 71-year-old man was treated for recurrent ventricular tachycardia with $200 \mathrm{mg}$ amiodarone daily for 15 months. During therapy, golden-grey deposits appeared in a vortex fashion in the corneal epithelium of both eyes just below the central cornea. His visual acuity had also decreased during the last 2 years from $20 / 20$ to $20 / 30$, accompanied by an altered colour perception, glare and blurring. $\mathrm{He}$ was referred to our clinic to see whether these changes could be attributed to the corneal deposits. Examination revealed opacity of both lenses and the described corneal findings. A diagnosis of bilateral senile cataract and cornea verticillita was made. After removal of the cataracts, visual acuity improved and visual symptoms disappeared; the corneal changes have remained stable under amiodarone therapy for the last 2 years (figure).

Corneal deposits may be observed in $70-100 \%$ of patients under amiodarone treatment but do not usually threaten vision or

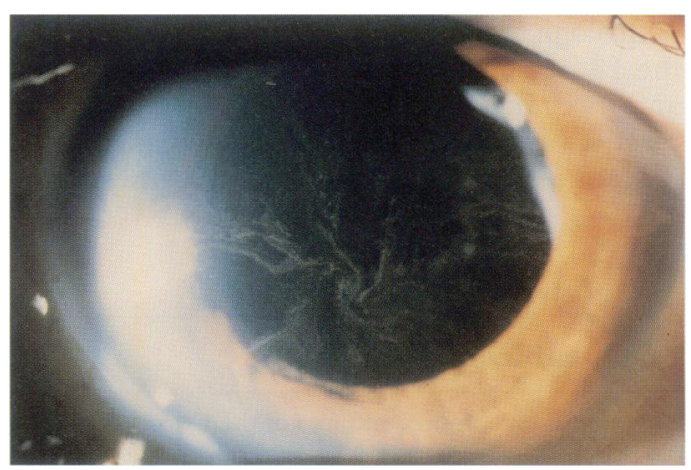

Photograph by Hans Künzli

need routine ophthalmologic surveillance.

DAVID GOLDBLUM JUSTUS G GARWEG

Department of Ophthalmology, University of Bern, Inselspital, 3010 Bern, Switzerland

Accepted 27 July 1998 